\title{
Collapse Disaster Risk Assessment of Changbai Mountain Region Based on GIS
}

\author{
LinaHan $^{1}$, Jiquan Zhang ${ }^{1}$, Yichen Zhang ${ }^{2}$, Zhijun Tong ${ }^{1}$, Si Alu ${ }^{1}$, Qing Ma ${ }^{1}$ \\ ${ }^{1}$ Natural Disaster Research Institute,School of Environment,Northeast Normal University \\ Changchun 130024, China \\ ${ }^{2}$ Jilin Institute of Geological Environment Monitoring, Changchun 130021, China
}

\section{基于 GIS 的长白山地区崩塌灾害风险评估}

\author{
韩丽娜 ${ }^{1}$, 张继权 ${ }^{1}$, 张以晨 ${ }^{2}$, 佟志军 ${ }^{1}$, 阿鲁思 ${ }^{1}$, 马晴 ${ }^{1}$ \\ ${ }^{1}$ 东北师范大学环境学院自然灾害研究所, 长春 130024 , 中国 \\ ${ }^{2}$ 吉林省地质环境监测总站, 长春 130021 , 中国
}

\begin{abstract}
Taking the Changbai Mountain Nature Reserve as the research area, based on the theory of modern disaster risk, the comprehensive use of GIS spatial analysis and disaster risk assessment mathematical methods, quantitative assessment of the risk of collapse disaster in Changbai Mountain area. Remote sensing data and socio-economic statistics data were applied to research. By analyzing the relationship between the risk of collapse disasters, exposure of the disaster-bearing bodies, vulnerability, and regional disaster prevention and reduction capabilities, the corresponding evaluation indicators were selected to construct a risk assessment model for the collapse hazards and drawdangerousand risk map in the Changbai Mountain area. The results show that the risk of collapse disaster is highest in the Tianchi Center of Changbai Mountain, and is higher in the north of Chibeidistrict and south of Chinandistrict.
\end{abstract}

Keywords: Changbai Mountain, Collapse, Risk assessment, Dangerousness, GIS.

\section{摘要}

以长白山自然保护区为研究区, 从现代 灾害风险理论出发, 综合运用 GIS 空间分析 和灾害风险评估数学方法, 对长白山地区的
崩塌灾害风险进行了定量评价。研究利用遥 感数据和社会经济统计数据。通过对崩塌灾 害的危险性、承灾体的暴露性、脆弱性以 及区域防灾减灾能力的关系分析, 选取相应 的评价指标, 构建崩塌灾害风险评价模型, 绘制出长白山地区崩塌灾害危险性及风险 性图。结果表明长白山地区崩塌灾害风险以 长白山天池中心最高, 以北池北区及池南区 以南较高分布。

关键词: 长白山, 崩塌, 风险评估, 危险性, GIS

\section{1. 引言}

崩塌是指陡崖上的岩土体在重力、降雨、 温度变化、地震、人类工程活动等因素的作 用下，造成岩体内裂隙扩展、发育，岩体强 度降低、随雨水滑落, 导致房屋建筑、道路、 桥梁、生命线工程等被砸毁的地质现象。随 着世界人口的急剧增长, 城市化进程的加快, 人类活动的空间需求范围逐步扩大, 如边坡 开挖、开采等工程活动, 外加气候等因素的 影响，崩塌灾害点分布愈来愈广、发生频率 愈来愈高、造成的生命财产损失也愈来愈大。 2007 年 4 月 4 日, 319 国道重庆彭水段山体 崩塌, 5000 吨巨石将公路路面连同路基破坏, 使交通中断,造成经济损失 1 亿元左右; 2012 年 8 月 17 日凌晨零时许，受近期降水诱发 以及融蚀的作用, 广东阳山县阳城镇环城社 
区二区后山高边坡松动的危岩体发生了一 经济损失约 130 万元, 10 户共 64 人受灾。 崩塌灾害带来的危害性显而易见, 目前, 针 对崩塌的研究工作主要包括崩塌的形成条 件、分类、破坏机理、运动特征、危险性评 价、治理技术等多个方面。张路青等 ${ }^{[1]}$ 对川 藏公路南线八宿至林芝段滚石的发生频率 进行了估计, 通过对遭遇滚石的概率及承灾 体的易损性分析, 获得车辆和行人经过不同 滚石区时遭遇滚石而致命的风险; 齐洪亮等 [2]将 GIS 技术和模糊综合评价法相结合用于 中国公路地质灾害危险性区划中。Pierson ${ }^{[2]}$ 等根据经验评分系统建立了最为简单的崩 塌发生地点预测评价模型; Azzoni [ $^{[2]}$ 等基于 刚性体的力学理论和二维的统计分析模型, 对崩塌的运动轨迹及一些相关的参数 (滚石 的能量、弹起的高度、运移距离) 进行了预 测。而基于 GIS 的山地区域崩塌灾害风险评 估研究较少。本研究综合考虑山地崩塌灾害 的发生机制和风险管理的需要, 建立了长白 山地区崩塌灾害风险评价指标体系, 应用自 然灾害风险指数法、加权综合评价法、层次 分析法, 基于 ArcGIS 构建了崩塌灾害风险 评价模型, 绘制长白山地区的崩塌灾害危险 性及风险图。在利用多因子评价的同时, 保 证了崩塌灾害风险指数对崩塌灾害发生空 间的反映。

\section{2 研究区概况}

研究区以长白山主峰为中心向四周延 伸 70 110km, 主要包括吉林省东南部的安 图县、抚松县和长白朝鲜族自治县的大部分 地区。地理坐标位置为北纬 $41^{\circ} 11^{\prime} \sim$ $43^{\circ} 00^{\prime}$, 东经 $127^{\circ} 16^{\prime} \sim 128^{\circ} 54^{\prime}$, 面 积 $3278 \mathrm{~km}^{2}$ 。气候类型属于中纬度中温带季 风半湿润气候; 地势总体趋势是以白云峰为 中心, 向四周逐渐降低, 总体特点是高差大、 切割深、坡度陡。在长白山主峰附近, 切割 深度可达 $300 \mathrm{~m}$ 以上, 山坡局部坡度达 $70^{\circ}$ 以上, 甚至近直立; 区内分布有新太古界、 中元古界、新元古界、古生界、中生界、新 生界; 区内出露有元古代、古生带、中生代、 新时代岩浆岩。研究区内崩塌地质灾害点共 有 71 个, 主要分布在公路边坡两侧, 长白
次大崩塌, 崩塌落石约 3000 立方米, 直接 山南坡、北坡的道路两侧和峡谷地带。结构 类型为块裂, 斜坡结构类型属于结晶岩类, 控制面结构为斜向或横向斜坡, 结构特征包 括节理裂隙面和䢃里面较多, 基岩以全新统 冰场组粗面岩为主。本研究选取长白山自然 保护区作为研究区, 主要考虑安图县、抚松 县和长白朝鲜族自治县三个地区 (图 1)。

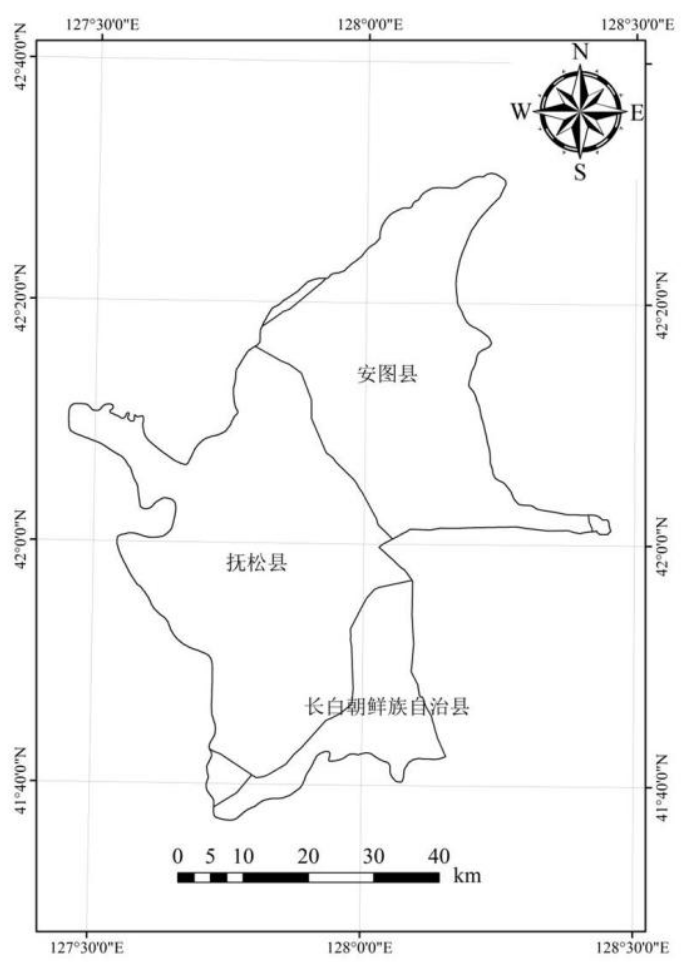

图 1 研究区示意图

\section{3 研究方法与数据来源}

\subsection{GIS 空间分析}

ArcGIS 具有强大的空间分析功能, 可 以对矢量数据进行缓冲区分析、叠置分析和 网络分析等; 对栅格数据进行距离制图、密 度制图和表面生成与分析等。同时，它可以 集成多种来源、多种尺度以及多种类别的数 据, 建立空间数据库, 方便地存储和提取评 价所需信息 ${ }^{[3]}$ 。本文利用 ArcGIS 叠置分析 对坡度、岩性等空间数据和社会人口经济等 属性数据进行综合处理。因子加权叠置法主 要是充分利用 GIS (地理信息系统) 能够对 地理数据进行采集、管理、查询、计算、分 析与可视化表现的功能, 在统一地理坐标基 础上对各因子指数绘图, 通过指数计算和图 层叠加 ${ }^{[4]}$, 绘制长白山地区崩塌风险图。 


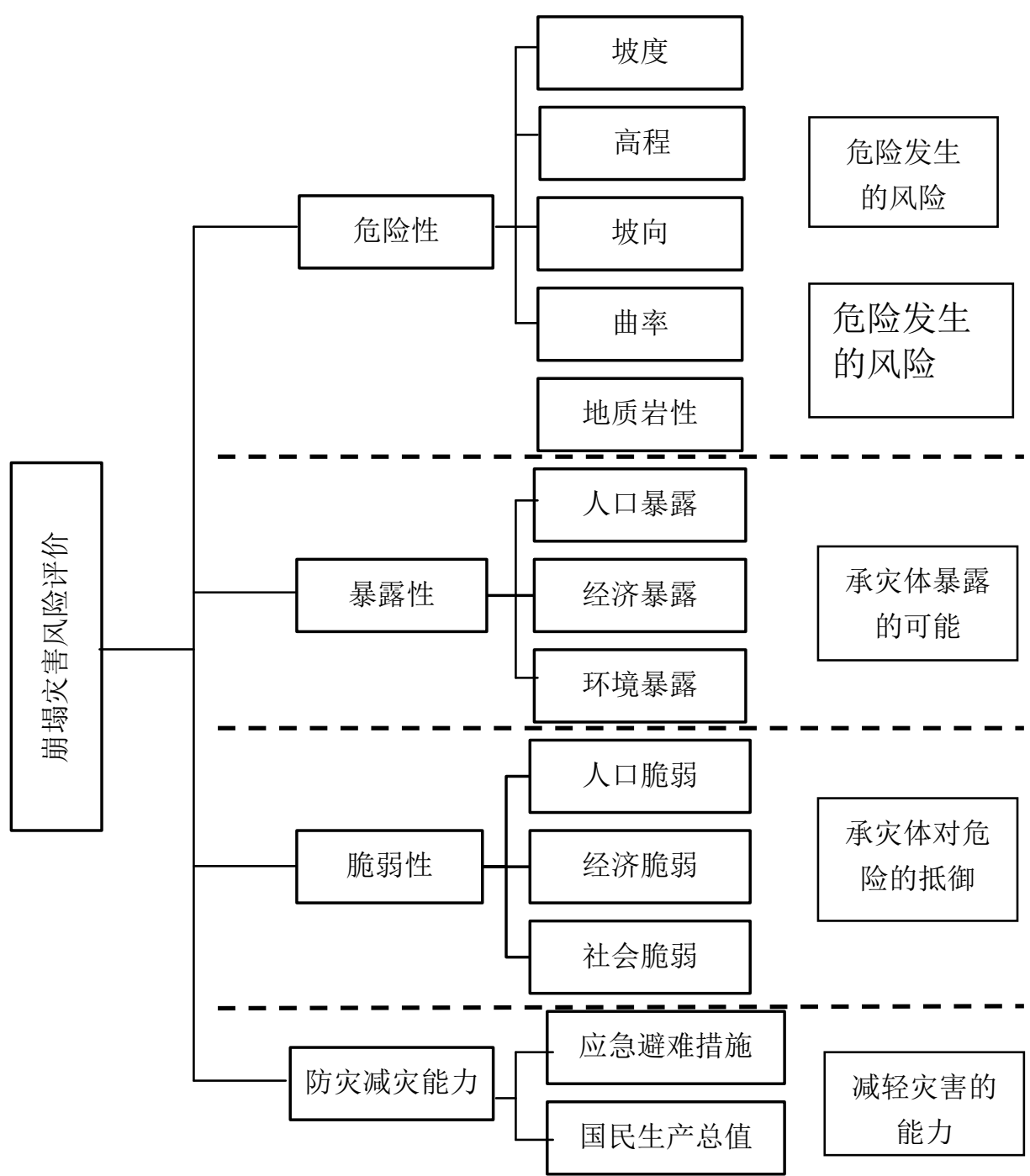

图 2 崩塌灾害风险的概念框架

表 1 崩塌灾害风险评价因子及权重值

\begin{tabular}{|c|c|c|c|c|}
\hline 目标层 & 因子层 & 权重 & 指标层 & 权重 \\
\hline \multirow{14}{*}{$\begin{array}{l}\text { 崩塌 } \\
\text { 灾害 } \\
\text { 风险 } \\
\text { 指数 }\end{array}$} & & & 坡度 & 0.406 \\
\hline & & & 高程 & 0.309 \\
\hline & 危险性 & 0.392 & 坡向 & 0.171 \\
\hline & & & 曲率 & 0.073 \\
\hline & & & 地质岩性 & 0.041 \\
\hline & & & 人口密度 & 0.493 \\
\hline & 暴露性 & 0.185 & 经济密度 & 0.311 \\
\hline & & & 农林牧副渔产值 & 0.196 \\
\hline & & & 0-18 岁、60 岁以上人口比例 & 0.415 \\
\hline & 脆弱性 & 0.238 & 受教育程度 & 0.106 \\
\hline & & & 耕地面积比例 & 0.293 \\
\hline & & & 自然保护区比例 & 0.186 \\
\hline & 防灾减 & 0.185 & 应急避难措施 & 0.5 \\
\hline & 灾能力 & & 国民生产总值 & 0.5 \\
\hline
\end{tabular}




\section{2 崩塌灾害风险评价指数的建立}

根据自然灾害风险的形成机理 ${ }^{[3]}$, 自然 灾害风险是危险性 $(\mathrm{H})$ 、暴露性 $(\mathrm{E})$ 、脆弱性 $(\mathrm{V})$ 防灾减灾能力 $(\mathrm{R})$ 综合作用的结果, 通 常采用自然灾害指数表征风险程度，可表示 为: 自然灾害风险指数 $=$ 危险性 $\cap$ 暴露性 $\cap$ 脆弱性 $\cap$ 防灾减灾能力。以自然灾害风险 4 因子概念为基准, 采用一定的数学方法集 成崩塌灾害风险评价相关的指标, 简化处理 它们之间的关系, 用以直观地表征崩塌灾害 风险程度。

$$
\mathrm{CDRI}=\left(\mathrm{H}^{\mathrm{WH}}\right)\left(\mathrm{E}^{\mathrm{WE}}\right)\left(\mathrm{V}^{\mathrm{WV}}\right)\left(\mathrm{R}^{\mathrm{WR}}\right)
$$

式中: CDRI 为崩塌灾害风险指数, 用于表征 灾害风险程度, 其值越大, 则崩塌灾害风险 程度越高; $H 、 E 、 V 、 R$ 分别为崩塌灾害风险 的危险性、暴露性、脆弱性和防灾减灾能力; WH、 WE、WV、WR 分别为危险性、暴露性、 脆弱性、防灾减灾能力因子的权重。

\section{3 数据来源}

本文所用到的数据有空间数据和属性 数据, 空间数据包括研究区行政区划图、坡 度图、高程图（DEM）、坡向图、岩性图、曲 率图; 属性数据包括社会人口经济统计数据。 空间数据资料主要来源于《吉林省长白山保 护开发区 $1: 5$ 万地质灾害调查与区划报告》, 属性数据资料来源于 《吉林省统计年鉴 2006-2016》。

\section{4 崩塌灾害风险评价}

\section{1 崩塌灾害风险的概念框架}

崩塌灾害风险是指崩塌灾害发生及造 成损失的不确定性。从灾害系统论出发, 自 然灾害风险是风险源和风险承受体综合作 用的结果 ${ }^{[5]}$ 。在此称之为崩塌灾害的危险性、 暴露性、承灾体的脆弱性和防灾减灾能力。 危险性是指致灾因子的活动规模、活动频次 以及对致灾因子产生影响的因素的状态; 暴 露性是指可能受到崩塌滑坡灾害威胁的所 有人或财产; 脆弱性表征面对崩塌滑坡灾害 暴露出的人或财产可能的损失大小; 防灾减 灾能力关注区域对崩塌滑坡灾害的应急准 备工作以及一定时期内能从灾害中恢复的 能力。根据实际情况, 建立本研究中的概念 框架如图 2 所示。

\section{2 崩塌灾害风险评价指标选取与量化}

崩塌滑坡灾害风险的因子指标与权重 系数表 1 所示。其中权重系数是通过对相关 领域专家进行问卷咨询, 以层次分析法 (AHP) 得出。层次分析法 (AHP) 是一种对指标进 行定性定量分析的方法。通过将每个因子的 组成指标成对地进行简单地比较、判断得出 对比矩阵并计算, 得出每个指标的权重, 以 确定不同指标对同一因子的相对重要性。长 白山区域崩塌灾害的危险性主要由于其特 殊的地形地貌, 加之降雨的诱导因子, 故选 取地形因子坡度、高程、岩性、断裂构造带, 曲率五个指标表征其危险性, 这里没有考虑 降雨的诱导性。长白山天池现今为我国著名 的旅游景区，是旅游资源、生态环境资源、 森林特产资源、水利水电资源、矿产资源的 聚集区, 由于该地区人为活动强烈, 故暴露 性综合考虑了人口暴露性、经济暴露性、环 境暴露性, 选取人口密度、经济密度、农林 牧副渔总产值三个指标。脆弱性主要考虑人 口脆弱性、经济脆弱性和社会脆弱性, 选取 0-18 岁, 60 岁以上人口比例、受教育程度

(中学及以上)、耕地面积比例、自然保护 区比例四个指标。防灾减灾能力考虑研究区 对于崩塌灾害发生后的防御应急能力, 考虑

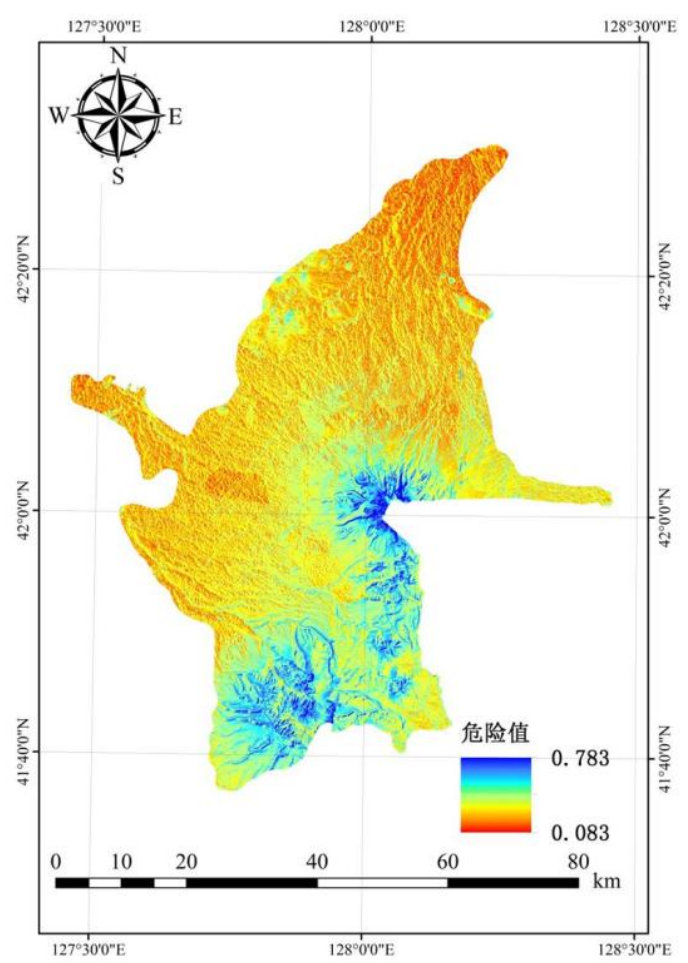

图 3 崩塌灾害危险性图 


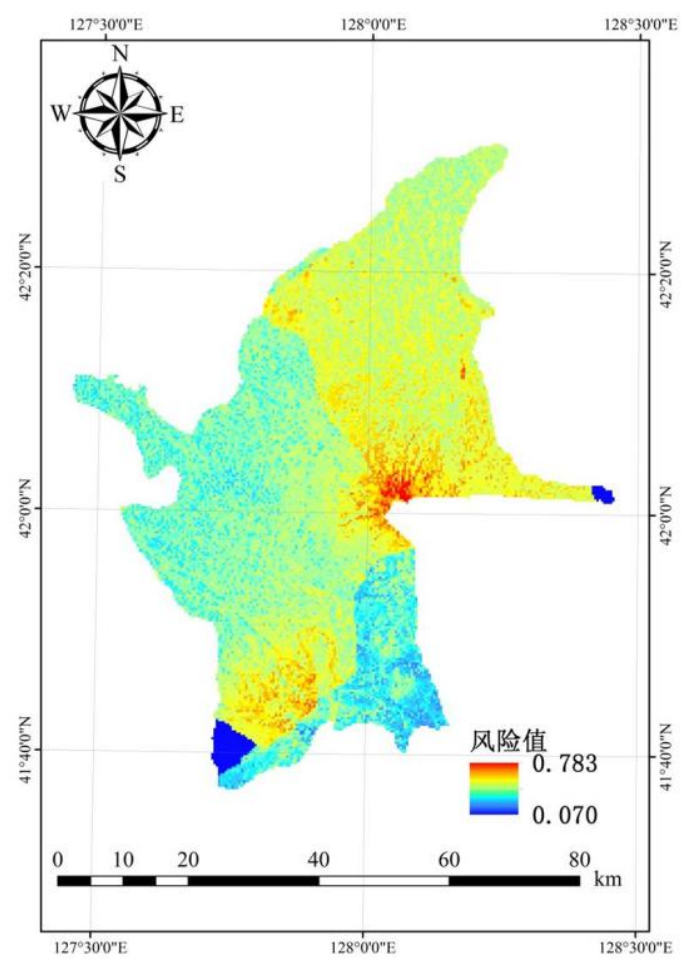

图 4 崩塌灾害风险图

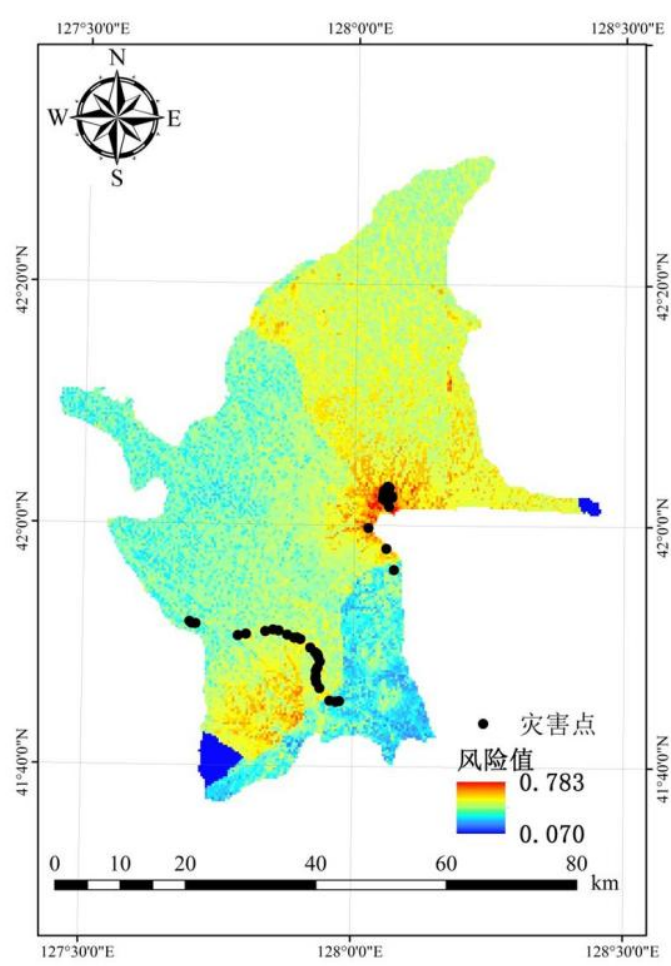

图 5 崩塌灾害历史发生点与风险图对比

应急救助措施及国民生产总值对于崩塌灾 害发生的应急响应能力, 选取医院床位数及 国民生产总值两个指标。由于数据的量纲不 一致, 对其进行去量钢化, 使用公式:

$$
\mathrm{X}^{\prime} \mathrm{ij}=\frac{((\mathrm{Xij}-\mathrm{Xmin}))}{(X \max -X \min )}
$$

式中: $X^{\prime} i j$ 为第 $i$ 个对象的第 $j$ 项指标; $X i j$ 为去量纲后第 $i$ 个对象的第 $j$ 项指标; Xmin 和 Xmax 分别指该指标的最小值和最大值。 使用 ArcGIS 对空间数据进行处理, 利用其 叠加分析功能、加权综合计算功能得出研究 区域总的崩塌危险性及风险性图。

\section{3 崩塌灾害风险指数计算}

根据崩塌灾害风险概念框架, 利用层次 分析法 (AHP) 和加权综合评价法求得崩塌灾 害风险指数。公式如前所述。其中危险性、 暴露性、脆弱性、防灾减灾能力计算公式如 下:

$$
\begin{gathered}
\mathrm{H}=\mathrm{W}_{\mathrm{H} 1} \mathrm{X}_{\mathrm{H} 1}+\mathrm{W}_{\mathrm{H} 2} \mathrm{X}_{\mathrm{H} 2}+\mathrm{W}_{\mathrm{H} 3} \mathrm{X}_{\mathrm{H} 3}+ \\
\mathrm{W}_{\mathrm{H} 4} \mathrm{X}_{\mathrm{H} 4}+\mathrm{W}_{\mathrm{H} 5} \mathrm{X}_{\mathrm{H} 5} \\
\mathrm{E}=\mathrm{W}_{\mathrm{E} 1} \mathrm{X}_{\mathrm{E} 1}+\mathrm{W}_{\mathrm{E} 2} \mathrm{X}_{\mathrm{E} 2}+\mathrm{W}_{\mathrm{E} 3} \mathrm{X}_{\mathrm{E} 3} \\
\mathrm{~V}=\mathrm{W}_{\mathrm{V} 1} \mathrm{X}_{\mathrm{V} 1}+\mathrm{W}_{\mathrm{V} 2} \mathrm{X}_{\mathrm{V} 2}+\mathrm{W}_{\mathrm{V} 3} \mathrm{X}_{\mathrm{V} 3} \\
\mathrm{R}=\mathrm{W}_{\mathrm{R} 1} \mathrm{X}_{\mathrm{R} 1}+\mathrm{W}_{\mathrm{R} 2} \mathrm{X}_{\mathrm{R} 2}+\mathrm{W}_{\mathrm{R} 3} \mathrm{X}_{\mathrm{R} 3}
\end{gathered}
$$

式中: $H 、 E 、 V 、 R 、 W H 、 W E 、 W V$ 、 $\mathrm{WR}$ 符号意义同前; 在 (3) ～(6) 式中, $\mathrm{Xi}$ 为指标 $\mathrm{i}$ 量化后的值, $\mathrm{Wi}$ 为指标 $\mathrm{i}$ 的权重, 表示各指标对形成崩塌灾害风险的主要因 子的相对重要性。

\section{4 长白山地区崩塌灾害危险性评价}

崩塌危险性分区图表征的是岩土体在 固有自然属性的作用下崩塌是否容易发生 的情况 ${ }^{[5]}$ 。基于地质和地形地貌等影响山体 崩塌发生的因素, 对长白山区域性崩塌进行 统计分析。选取坡度、高程、坡向、曲率、 岩土体类型五个影响崩塌发生的因素, 根据 表 1 中各个指标权重值, 利用 ArcGIS 进行崩 塌危险性绘图 (图 3), 从图中可以看出长白 山天池中心及沿着鸭绿汇一带和池南区以 南地区危险性较高, 主要原因可能是长白山 天池中心高程高、坡度大, 地势险峻导致易 于发生崩塌, 池南区以南地区由于坡度较大 利于崩塌灾害的发生。

\section{5 长白山地区崩塌灾害风险性评价}

长白山地区崩塌灾害风险的区划是建 立在对崩塌灾害危险性、暴露性、脆弱性, 以及防灾减灾能力的综合分析之上的, 对于 该区域的风险分析, 得出来的是相对的结果。 对崩塌灾害风险因子进行有机的耦合得出 集成化指数 CDRI, 依据崩塌灾害风险评价 模型, 利用 ArcGIS 制作长白山地区风险图。 
（图 4）结果得出天池中心风险值最高, 池 北区大部分地区和池南区小部分地区风险 值较高, 天池中心风险值较高的原因在于其 高程高, 坡度大, 地势险峻, 其地形特征利 于崩塌灾害的发生, 池北区分布在安图县内, 该地区人口较多, 经济较发达, 导致该区暴 露性与脆若部分地区由于坡度较大, 危险性 值较大，故风险值较高。大多高风险区与高 危险区重合，进一步表明危险性在四个因子 里的重要性。

\section{5 崩塌灾害风险评价模型验证}

为了检验研究中提出的崩塌灾害风险 评价法和模型的适用性, 以长白山地区最近 几年的崩塌灾害发生点与所绘制的风险图 进行对比 (图 5), 发现两者匹配度较好, 个 别灾害发生在高风险区域以外, 可能原因是 由于资料有限, 没有考虑降雨对于崩塌灾害 发生的诱导性。因此, 本文通过指标选取, 利用自然灾害风险指数法、层次分析法和加 权综合评价法建立模型进行崩塌灾害危险 与风险评价是合理的。在数据允许的情况下, 可以依据此模型来评价不同地区崩塌灾害 发生的危险性与风险性。

\section{6 结论}

利用风险形成的危险性、暴露性、脆弱 性和防灾减灾能力 4 因子对区域崩塌灾害 风险进行评价, 不仅可以集成崩塌灾害风险 指数用以反映崩塌灾害风险在空间上的分 布情况, 而且可以根据相应地理位置上各 项指标的差异，分析地区风险性高的原因， 从而方便灾害风险管理与防灾物资分配。由 于对崩塌灾害风险的理解以及资料有限等 原因, 本文的指标选取考虑可能不全面, 虽 然依据现有数据对长白山地区的灾害风险 选取相应评价指标进行危险性和风险性的 评价, 但在指标选取、权重系数方面, 难免 有主观因素与考虑不足。应该综合考虑影响 崩塌灾害发生的一切因素, 提高研究精度。 对于大区域的崩塌灾害风险研究, 有利于从 宏观角度认识了解崩塌灾害风险, 进行以区 域为对象的宏观防灾减灾规划。同时, 在此 基础上对已评价出的高风险小区域的崩塌
灾害风险研究成果则可以更好地为实际生 产生活提供帮助。

\section{Acknowledgements}

This study was supported by The Key Scientific and Technology Program of Jilin Province (20170204035SF); The Key Scientific and Technology Research and Development Program of Jilin Province (20180201033SF).

\section{致谢}

本文得到吉林省重点科技攻关项目 （20170204035SF）和吉林省重点科技研发 项目（20180201033SF）的资助。

*通讯作者: 张继权 (1965-), 教授, 博士 生导师, 主要从事环境灾害风险评价与管理、 预警等方向研究, 邮箱: zhang.jq022@nenu.e du. cn。

\section{参考文献}

[1] 张路青, 杨志法, 张英俊, 公路沿线遭 遇滚石的风险分析一方法研究, 岩石力 学与工程学报, (24):5544-5548,2005.

[2]齐洪亮，尹超，田伟平等，基于 ArcGIS 的中国公路地质灾害危险性区划, 长安 大学学报 (自然科学版), 35(5): $22-$ 27,2015 .

[3]蒋新宇，范久波，张继权等，基于 GIS 的松花江干流暴雨洪涝灾害风险评估, 灾害学, 24(3):51-56,2009.

[4]Li Xinghua, Wu Wenjie, LvDibo, Zhang Cunhou, Research on risk assessment and regionalization of forest and grassland fires, Journal of Risk Analysis and Crisis Response,2(1):69-77,2012.

[5]Guo Jun, Huang Chongfu, Time limit of the probabilistic risk for natural disaster, Journal of Risk Analysis and Crisis Response,7(3):137-145,2017.

[6]TianYingying, Xu Chong, Chen Jian, Regional Risk Assessment of Earthquaketriggered Landslides, Journal of Risk Analysis and Crisis Response, 5(4): 234245, 2015. 